\title{
Skilled Manpower Selection for Micro, Small and Medium Enterprises: A Fuzzy Decision Making Approach
}

\author{
Monalisha Pattnaik \\ Dept. of Business Administration \\ Utkal University, Bhubaneswar, India-751004 \\ E-mail : monalisha_1977@yahoo.com
}

\begin{abstract}
Supply of skilled manpower is a major strategy for entrepreneur to run the production process smoothly. Skilled manpower categorization, selection and performance evaluation are decisions of strategic importance to micro, small and medium enterprises. Global competition, mass customization, high customer expectations and harsh economic conditions are forcing enterprises to rely on external skilled manpower to contribute finished products and to manage a growing number of processes and functions that were once controlled internally. Thus skilled manpower performance evaluation is very important to choose the right manpower for the right enterprises. In this paper a fuzzy manpower selection algorithm (FMSA) is implemented to rank the technically efficient manpower according to the both predetermined performance criteria and additional skilled-related performance criteria. The algorithm is based on calculating fuzzy suitability indices for the efficient manpower alternatives, and then, ranking the fuzzy indices to select the best skilled manpower alternative. A comprehensive example is provided to illustrate the decision making procedure.
\end{abstract}

Keywords:Fuzzy Logic Performance Evaluation, manpower selection, defuzzification

\section{INTRODUCTION}

In real world, the company often makes use of manpower selection on fuzzy decision space to promote their commodities. The selection of skilled manpower of enterprise is an important issue to enterprise itself. The main role of selecting manpower in a business enterprise is to support the business and production activities by providing continuous material and service flow. Because a typical manufacturing company spends $60 \%$ of its sales on purchasing materials, goods and services from external manpowers, the quality, cost and other aspects of the endproduct is influenced by manpowers' performance. Consequently the results of obtaining a bad decision about selecting manpower are resulting more severe with the increasing dependency of the organizations on manpowers.

Thus, selecting and manufacturing strategies must be compatible with each other and should support the competitive strategies at all levels of the organization. This means the operation / production department, marketing department, and finance department in an enterprise jointly to determine these decisions. Therefore the decision-making involves selecting the right manpower, marketing, inventory and financing issues. So, an investigation of this integrated model is very important and valuable to the enterprise. However, the most important thing is that selecting concepts and functions must be put into operation and set within a realistic system. To ensure this the decision process of purchasing must be modeled and structured in a realistic way. In addition, today's purchasing literature; various works have been compiled about the modeling of manpower selection and facilitating decision making. For the last 10 years, use of artificial intelligence (AI) techniques in increasing. Therefore, it makes economic sense for enterpriser or decision maker to use fuzzy logic, one of the AI techniques, has a limited use in this research.

This paper tries to adopt fuzzy arithmetic approach for modeling the manpower selection of the organization. Here, initially, the literature about purchasing and manpower selection topic is presented and later, the fuzzy logic method adopted in modeling manpower selection process will be explained. Finally a numerical example will be given in order to illustrate the decision procedure and managerial insights are drawn.

\section{LITERATURE REVIEW ON MANPOWER SELECTION}

An early study of manpower selection in production process is discussed in three categories by Weber (1991).

i) Manpower Selection Criteria

ii) Purchasing environments

iii) Appropriate decision techniques.

The approach helps the decision maker to find different method to use in multiple areas according to different situations. From this categorization, the manpower selection process can be separated into four steps De Boer (1998):

1. Finding out what exactly I want to achieve with the manpower selection.

2. Determining the Criteria

3. Pre-evaluation of the suitable man powers

4. Final choice.

Most of the decision models in the literature are developed to be applied in the final choice of the purchasing process. Maximum selection models are characterized as 'single-deal' or 'package' models and most of the decision methods focused on solving these models De Boer (2001). On the other hand, one of the methods used in manpower selection is total cost of ownership (TCO) models. TCO- 
based models try to take costs that will be received during the life cycle of the purchased product into account. Three separations can be made about these costs.

1. Costs before the process

2.Costs during the process

3.Costs after the process Ellram and Carr (1994)

Another decision method used for manpower selection is mathematical programming (MP) models. But Timmerman proposed the Cost-rate method' for companies that have computer accounting systems Timmerman (1986). Above all, Monczka et al. (1998) and Smytka and Clemens (1993) suggested a model that combines the TCO approach and scoring systems for a special costing case. But MP models are more objective than the scoring methods but these models take only quantitative criteria into account.

Statistical models are another method that deals with the stochastic uncertainty in manpower selection. Ronen and Trietsch (1988) discussed a decision support system for the situations when only order delivery time is uncertain Weber (1991) proposed a statistical simulation model that presents a solution for uncertain demand situations.

Pan (1989), Chaudhry et al. (1993), Rosenthal (1995), Sadrian and Yoon (1994) and Weber and Desai (1996) introduce models that assumed predetermined levels of quality, service and delivery constraints. Weber et al. (2000) combine the MP and the DEA methods to provide buyers with a tool for negotiations with man powers that were not selected right away as well as to evaluate different numbers of man powers to use. Khanle and Vaingankar (2006) introduce the procedure for estimating availability of middle level skilled manpower. Giuliana and Francesco (2012) discuss that some policy recommendations should be employed to the young people, the disabled, and immigrant workers. Núria and Silvio (2012) present the occupational selection in multilingual labor markets in Catalonia. Vicente et al. (2012) define the commitment to employees, labor intensity, and labor productivity in small firms by using a non-linear approach.

As a matter of fact another solution to the manpower selection problem is AI-based models. Neural networks and expert systems are examples of AI-based methods. Albino and Garavelli (1998) propose a decision support system based on neural networks while Vokurka et al. (1996) developed an expert system that is able to support the decision maker in the manpower choice phase. In addition, Khoo et al. (1998) proposed an internet-based agent system for manpower selection. Zenz (1981) and Timmerman (1986) refer to this model in their purchasing books. In the literature there are some methods proposing the use of an analytical hierarchy process (AHP) i.e. Narasimhan (1983), Nydick and Hill (1992), Baldwin and Guild (1979) an analytical network process (ANP) i.e. Sarkis and Talluri (2000) and statistical methods i.e. Williams (1984), Min (1994) and Petroni and Braglia (2000) together with linear weighting models in order to compensate for some disadvantages of the weighting model. Finally, some authors suggest using fuzzy set theory to model the uncertainty of manpower selection De Boer (1998), Li et al. (1997), Hienet al. (2009) and Holt (1998) have studied by applying these methods.

\section{METHODS AND PROCEDURE OF MANPOWER PERFORMANCE EVALUATION}

\subsection{Methodology}

Before shifting to the manpower selection approach some methods utilized in this approach are briefly introduced in this section.

\subsubsection{Fuzzy Set Theory}

Fuzzy set theory was initially introduced by Zadeh (1965) to deal with problems involving the absence of sharply defined criteria. Subsequently, the improvement and application of fuzzy numbers was studied by Dubois and Prade (1983) and some fuzzy implicated models are derived in Pattnaik (2012).

\subsubsection{Trapezoidal Fuzzy Numbers}

In a universe of discourse of $\mathrm{X}$, a fuzzy subset $\mathrm{A}$ of $\mathrm{X}$ is characterized by a membership function $f_{A}$, which maps each element $\mathrm{X}$ in $\mathrm{X}$ to a real number in the interval $[0,1]$. The function value represents the grade of membership of $x$ in $\mathrm{A}$.

A fuzzy number A Chaudhry et al. (1993) and Chen (1958) in < (real line) is a trapezoidal fuzzy number if its membership function $f_{A}: R \rightarrow[0,1]$ is

$$
f_{A}(x)=\left\{\begin{array}{cc}
(x-c) /(a-c), & c \leq x \leq a \\
1, & a \leq x \leq b \\
(x-d) /(b-d), & b \leq x \leq d \\
0, & \text { otherwise }
\end{array}\right.
$$

With $-\infty<c<a<b<d<\infty$ the trapezoidal fuzzy number A, shown in figure 1 , can be represented by (c, a, b, d).

The strongest grade of membership is for the trapezoidal fuzzy number $A$ in the interval [a, b], i.e. $f_{A}(x)=1 ; x \in[a, b]$; this is the highest possible value of evaluation data. In addition, $c$ and $d$ are the lower and upper bounds of the available area for the evaluation data. They are used to reflect the fuzziness of the evaluation data. The narrower the interval $[c, a]$ and $[b, d]$, the lower the Fuzziness of the evaluation data.

By the extension principle, the extended algebraic operations of any two trapezoidal fuzzy numbers $A=(c, a, b$, $\mathrm{d})$; and $\mathrm{B}=(\mathrm{g}, \mathrm{e}, \mathrm{f}, \mathrm{h})$ can be expressed as:

$$
\begin{aligned}
& \text { Addition } \oplus: A \oplus B=(c+g, a+e, b+f, d+h) \\
& \begin{array}{l}
\text { Multiplication } \otimes: \\
\quad=(\mathrm{Kc}, \mathrm{Ka}, \mathrm{Kb}, \mathrm{Kd} \otimes \mathrm{A}=\mathrm{K} \otimes(\mathrm{c}, \mathrm{a}, \mathrm{b}, \mathrm{d})
\end{array}
\end{aligned}
$$




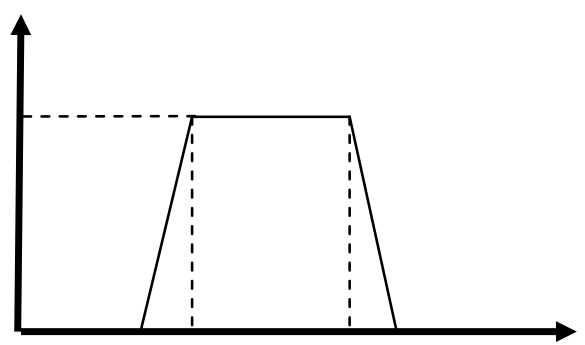

Figure 1. A sample of trapezoidal fuzzy number

\subsubsection{Fuzzy Logic Operators}

When fuzzy sets are used in the decision making problem, the idea of trade-offs between conflicting criteria are realized with the help of fuzzy logic operators (f.l.o.) [50] and [43] when compensation is allowed. The first one introduced by Zadeh (1965) are min, max and $1-\mu$ ( $\mu$ is the membership degree to a given fuzzy set). However, the degree compensation through which human aggregate criteria is not expressed by these operators. There exists some (f.l.o.) that more accurately represent human decision making. Weighted mean and maxmin Zimmerman and Zysno (1983) and Von Altrock (1997) are the examples of averaging operators, Weighted mean operator is a convex composition of several fuzzy sets with coefficients that express the 'percentage' of a given set in the aggregating set. The formulation of the weighted mean operator is shown below:

$\mu_{i}(x)=\sum_{j=1}^{m} c_{j} \mu_{i j}(x), \sum_{j=1}^{m} c_{j}=1, i=1,2, \ldots, n$

\subsubsection{Linguistic Variables}

A Linguistic variable is a variable whose values are expressed in terms of words or sentences instead of numbers. The concept of linguistic variable is very useful in situations where decision problems are too complex or too ill-defined to be described properly using conventional quantitative expressions. For example, the performance ratings of alternatives on qualitative attributes could be expressed using linguistic variable such as very poor, poor, fair, good, very good, excellent etc. Such linguistic values can be represented using positive triangular fuzzy numbers. For example 'poor' and 'very good' can be represented by the positive trapezoidal fuzzy numbers $(0.2,0.3,0.4,0.5)$ and $(0.6,0.8,0.9,1.0)$, respectively.

\subsubsection{Ranking Method}

In order to elicit the magnitude of the numbers in a fuzzy number group a ranking method should be introduced. The literature review reveals that magnitudes of fuzzy set ranking methods exist i.e. Barbarosoglu and Yazgac (1997), Chen (1958), Campos and Munoz (1989), Kim and Park (1990), Li et al. (1997), Liang and Wang (1991), Lin and Juang (2008), Chang and Lee (1994), Fortemps and Roubens (1996), Peneva and Popchev (1998) and Weber (1991). One of the most common methods for ranking is Chen's method. Chen (1958) Ranking method is chosen for this study due to its easy usage and efficient results.

\subsection{Procedures}

The manpower selection approach is based on the method of collecting the subjective evaluations of single or multiple decision makers in order to reach a final choice. In the method, $n$ decision makers evaluate the performance of the $\mathrm{m}$ supplies in $\mathrm{k}$ criteria and rate the importance of the $\mathrm{k}$ criteria in linguistic expression. Furthermore, linguistic expressions are converted into fuzzy numbers, processed in provided formulas and finally the performance ranking of the man powers are obtained. The execution steps of the method are:

I) Determination of the importance degree of the performance criteria in linguistic expressions.

II) Determination of the performance of man powers in each criterion in linguistic expressions.

III) Fuzzification of the criteria's importance degrees and performance evaluations.

IV) Aggregation of the criteria importance weights with fuzzy mean operator.

V) Aggregation of the performance evaluations for each criterion with fuzzy mean operator.

VI) Aggregation of the importance weights and performance evaluations with fuzzy weighted mean operator and obtaining fuzzy preference index.

VII) Defuzzification and ranking of the required fuzzy preference index for each manpower alternative.

\section{Steps I-II Determining the Importance Degrees and Performances}

Throughout the method, I assume that there are $n$ decision makers (purchasing experts) who assess the importance weights of $\mathrm{k}$ criteria and the performances of $\mathrm{m}$ manpower alternatives. The decision makers use a set of weights, $\mathrm{W}=(\mathrm{VL}, \mathrm{L}, \mathrm{M}, \mathrm{H}, \mathrm{VH})$ to appraise $W_{t i}$ weights of $\mathrm{k}$ criteria. Here, VL indicates very low, $\mathrm{L}$ low, $\mathrm{M}$ middle, $\mathrm{H}$ high and $\mathrm{VH}$ very high linguistic expressions for importance weights of criteria. The membership functions and system parameters of these fuzzy linguistic variables are:

$$
\begin{aligned}
& \mathrm{VL}:(0,0,0,0.2) \\
& \mu_{V L}(x)=\left\{\begin{array}{cc}
1-5 x, & 0 \leq x \leq 0.2 \\
0, & \text { otherwise }
\end{array}\right.
\end{aligned}
$$

$\mathrm{L}(0,0.2,0.2,0.4)$

$$
\mu_{L}(x)=\left\{\begin{array}{cc}
5 x, & 0 \leq x \leq 0.2 \\
2-5 x, & 0.2 \leq x \leq 0.4 \\
0, & \text { otherwise }
\end{array}\right.
$$


M: $(0.3 ., 0.5,0.5,0.7)$

$$
\mu_{M}(x)=\left\{\begin{array}{cc}
5 x-3 / 2, & 0.3 \leq x \leq 0.5 \\
7 / 2-5 x, & 0.5 \leq x \leq 0.7 \\
0, & \text { otherwise }
\end{array}\right.
$$

$\mathrm{H}:(0.5,0.8,0.8,1)$

$$
\mu_{H}(x)=\left\{\begin{array}{cc}
\frac{10 x}{3}-\frac{5}{3}, & 0.5 \leq x \leq 0.8 \\
5-5 x, & 0.8 \leq x \leq 1 \\
0, & \text { otherwise }
\end{array}\right.
$$

VH: $(0.8,1,1,1)$

$$
\mu_{V H}(x)=\left\{\begin{array}{cc}
5 x-4, & 0.8 \leq x \leq 1 \\
0 & \text { otherwise }
\end{array}\right.
$$

$\mathrm{Wt}_{\mathrm{j}}=$ Linguistic value given by $\mathrm{j}$ decision maker for $\mathrm{t}$ criterion.

$\mathrm{Wt}_{\mathrm{j}}=c_{t_{j}}, a_{t_{j}}, b_{t_{j}}, d_{t_{j}}, \quad \mathrm{t}=1,2, \ldots, \mathrm{K}, \mathrm{j}=1,2, \ldots, \mathrm{n}(8)$

This scale is chosen because of its best fit with the previous usage in recent articles Liang and Wang (1991). For determining manpower performances, $\mathrm{n}$ decision makers assess the $A_{i t}$ subjective performance values of $m$ manpower according to their previous experience and opinions. Here this paper uses the 9 scale of Liang and Wang (1991) for linguistic values.

The variable set for performance evaluation is $\mathrm{A}=(\mathrm{VP}$, VP \& P, P P \& M, M, M\&G, G, G \& VG, VG). Here VP indicates very poor, VP \& $\mathrm{P}$ between very poor and poor, $\mathrm{P}$ poor, $\mathrm{P} \& \mathrm{M}$ between poor and middle, $\mathrm{M}$ middle, $\mathrm{M} \& \mathrm{G}$ between middle and good, G good, G\&VG between good and very good, and VG very good. The membership functions and system parameters of these linguistic variables are

VP: $(0,0,0,0.2)$

$$
\mu_{V P}(x)=\left\{\begin{array}{c}
1-5 x, 0 \leq x \leq 0.2 \\
0, \quad \text { otherwise }
\end{array}\right.
$$

VP \& P: $(0,0,0.2,0.4)$

$$
\mu_{V P \& P}(x)=\left\{\begin{array}{cc}
1, & 0 \leq x \leq 0.2 \\
2-5 x, & 0.2 \leq x \leq 0.4 \\
0, & \text { otherwise }
\end{array}\right.
$$

P: $(0,0.2,0.2,0.4)$

$$
\mu_{P}(x)=\left\{\begin{array}{cc}
5 x, & 0 \leq x \leq 0.2 \\
2-5 x, & 0.2 \leq x \leq 0.4 \\
0, & \text { otherwise }
\end{array}\right.
$$

P \& M: $(0,0.2,0.5,0.7)$

$$
\mu_{P \& M}(x)=\left\{\begin{array}{cc}
5 x, & 0 \leq x \leq 0.2 \\
1, & 0.2 \leq x \leq 0.5 \\
7 / 2-5 x, & 0.5 \leq x \leq 0.7 \\
0, & \text { othrewise }
\end{array}\right.
$$

M: $(0.3,0.5,0.5,0.7)$

$$
\mu_{M}(x)=\left\{\begin{array}{cc}
5 x-3 / 2, & 0.3 \leq x \leq 0.5 \\
7 / 2-5 x, & 0.5 \leq x \leq 0.7 \\
0, & \text { otherwise }
\end{array}\right.
$$

M \& G: $(0.3,0.5,0.8,1)$

$$
\mu_{M \& G}(x)=\left\{\begin{array}{cc}
5 x-3 / 2, & 0.3 \leq x \leq 0.5 \\
1, & 0.5 \leq x \leq 0.8 \\
5-5 x, & 0.8 \leq x \leq 1 \\
0, & \text { othrewise }
\end{array}\right.
$$

$\mathrm{G}:(0.6,0.8,0.8,1)$

$$
\mu_{G}(x)=\left\{\begin{array}{cc}
5 x-3, & 0.6 \leq x \leq 0.8 \\
5-5 x, & 0.8 \leq x \leq 1 \\
0, & \text { otherwise }
\end{array}\right.
$$

G \& VG: $(0.6,0.8,1,1)$

$$
\mu_{G \& V G}(x)=\left\{\begin{array}{cc}
5 x-3, & 0.6 \leq x \leq 0.8 \\
1, & 0.8 \leq x \leq 1 \\
0, & \text { otherwise }
\end{array}\right.
$$

VG: $(0.8,1,1,1)$

$$
\mu_{V G}(x)=\left\{\begin{array}{c}
5 x-4,0.8 \leq x \leq 1 \\
0 \quad \text { otherwise }
\end{array}\right.
$$

$\mathrm{A}_{\mathrm{itj}}=$ the linguistic value, given by $\mathrm{j}$ decision maker, of $\mathrm{i}$ manpower for $\mathrm{t}$ criterion. 


$$
\begin{gathered}
A_{i t j}=\left(q_{i t j}, o_{i t j}, p_{i t j}, r_{i t j}\right) \\
\left\{\begin{array}{l}
i=1,2, \ldots m \\
t=1,2, \ldots k \\
j=1,2, \ldots n
\end{array}\right.
\end{gathered}
$$

\section{Step III Fuzzification}

The given performance values and criteria weights are converted into trapezoidal fuzzy numbers according to the determined evaluation scale.

\section{Step IV-V Aggregation of Importance Weights and Performance Evaluations}

Performance values and criteria weights assessed by the decision makers are aggregated separately for each $c_{t}(t=1$, $2 \ldots, \mathrm{k})$ criterion by the fuzzy mean operator and thereby, for each criterion, $\mathrm{W}_{\mathrm{t}}$ fuzzy weight and $\mathrm{A}_{\mathrm{it}}$ fuzzy performance values are obtained. The formulations and parameter of the calculations are:

$$
\begin{aligned}
& W_{t}=\left(\frac{1}{n}\right) \otimes\left(W_{t 1} \otimes W_{t 2} \otimes \ldots \otimes W_{t n}\right), \mathrm{t}=1,2, \ldots . \mathrm{k} \\
& W_{t}=\left(c_{t}, a_{t}, b_{t}, d_{t}\right), \quad c_{t}=\sum_{j=1}^{n} \frac{c_{t j}}{n}, \\
& \mathrm{a}_{\mathrm{t}}=\sum_{\mathrm{j}=1}^{\mathrm{n}} \frac{\mathrm{a}_{\mathrm{tj}}}{\mathrm{n}}
\end{aligned}
$$$$
b_{t}=\sum_{j=1}^{n} \frac{b_{t j}}{n}
$$$$
d_{t}=\sum_{j=1}^{n} \frac{d_{t j}}{n}
$$$$
A_{t}=\left(\frac{1}{n}\right) \otimes\left(A_{i t 1} \otimes A_{i t 2} \otimes \ldots \otimes A_{i t n}\right)
$$$$
\mathrm{i}=1,2, \ldots ., \mathrm{m}, \mathrm{t}=1,2, \ldots ., \mathrm{k}
$$

$A_{i t}=\left(q_{i t}, o_{i t}, p_{i t}, r_{i t}\right)$,

$$
\mathrm{q}_{\mathrm{it}}=\sum_{\mathrm{j}=1}^{\mathrm{n}} \frac{\mathrm{q}_{\mathrm{itj}}}{\mathrm{n}}
$$$$
o_{i t}=\sum_{j=1}^{n} \frac{o_{i t j}}{n}
$$

$$
\begin{aligned}
& p_{i t}=\sum_{j=1}^{n} \frac{p_{i t j}}{n} \\
& r_{i t}=\sum_{j=1}^{n} \frac{r_{i t j}}{n}, \mathrm{i}=1,2, \ldots . \mathrm{m}, \mathrm{t}=1,2, \ldots ., \mathrm{k}
\end{aligned}
$$

\section{Step-VI Obtaining Fuzzy Preference Index}

After steps IV \& V, importance weights and performance values are aggregated together with fuzzy mean operator in order to obtain a fuzzy preference index. These operations are defined as:

$F_{i}=\left(\frac{1}{k}\right) \otimes\left[\left(A_{i 1} \otimes W_{1}\right) \otimes\left(A_{i 2} \otimes W_{2}\right) \otimes \ldots \ldots . \otimes\left(A_{i n} \otimes W_{n}\right)\right]$

According to the extension principle of Timmerman (1986), $F_{i}$ is fuzzy number with membership function.

$\mu_{F_{i}}(x)=\left\{\begin{array}{cc}-H_{i 1}+\left[H_{i 1}^{2}+\left(x-y_{i}\right) / T_{i 1}\right]^{1 / 2}, & Y_{i} \leq x \leq Q_{i} \\ 1, & Q_{i} \leq x \leq R_{i} \\ H_{i 2}+\left[H_{i 2}^{2}+\left(x-z_{i}\right) / U_{i 1}\right]^{1 / 2}, & R_{i} \leq x \leq Z_{i} \\ 0, & \text { otherwise }\end{array}\right.$

$\mathrm{i}=1,2 \ldots . \mathrm{m}$

$F_{i}=\left(Y_{i}, O_{i}, R_{i}, Z_{i}, H_{i 1}, H_{i 2}, U_{i 1}\right), i=1,2, \ldots . ., m$

Here $\mathrm{T}_{\mathrm{i} 1}, \mathrm{~T}_{\mathrm{i} 2}, \mathrm{U}_{\mathrm{i} 1}, \mathrm{U}_{\mathrm{i} 2}, \mathrm{Y}_{\mathrm{i}}, \mathrm{O}_{\mathrm{i}}, \mathrm{R}_{\mathrm{i}}, \mathrm{Z}_{\mathrm{i}}, \mathrm{H}_{\mathrm{i} 1}$ and $\mathrm{H}_{\mathrm{i} 2}$ values are calculated as:

$$
\begin{aligned}
& T_{i 1}=\sum_{i=1}^{k} \frac{\left(o_{i t}-q_{i t}\right)\left(a_{t}-c_{t}\right)}{k} \\
& T_{i 2}=\sum_{i=1}^{k} \frac{\left[q_{i t}\left(a_{t}-c_{t}\right)+c_{t}\left(o_{i t}-q_{i t}\right)\right]}{k} \\
& U_{i 1}=\sum_{i=1}^{k} \frac{\left(r_{i t}-p_{i t}\right)\left(d_{t}-b_{t}\right)}{k} \\
& U_{i 2}=\sum_{i=1}^{k} \frac{\left[d_{t}\left(p_{i t}-r_{i t}\right)+r_{i t}\left(b_{i}-d_{i}\right)\right]}{k} \\
& Y_{i}=\sum_{i=1}^{k} \frac{q_{i t} \cdot c_{t}}{k} \\
& o_{i}=\sum_{i=1}^{k} \frac{o_{i t} \cdot a_{t}}{k}
\end{aligned}
$$




$$
\begin{aligned}
& R_{i}=\sum_{i=1}^{k} \frac{p_{i t} \cdot b_{t}}{k} \\
& Z_{i}=\sum_{i=1}^{k} \frac{r_{i t} \cdot d_{t}}{k} \\
& H_{i 1}=\frac{T_{i 2}}{\left(2 T_{i 1}\right)} \\
& H_{i 2}=\frac{U_{i 2}}{\left(2 U_{i 1}\right)}
\end{aligned}
$$

It can be examined that $\mathrm{F}_{\mathrm{i}}$ fuzzy preference index is not actually a trapezoidal fuzzy number. In order to obtain this, the approximation below can be written: $F \approx\left(Y_{i}, O_{i}, R_{i}, Z_{i}\right)$

\section{Step - VII, Defuzzification and Ranking of the Preference Index}

Defuzzification of trapezoidal fuzzy numbers of $F_{i}$ index that is calculated for each manpower alternative and the ordering or ranking of these crisp numbers is the last operations of the manpower selection method.

Chen (1958) proposed a method that defuzzifies and ranks the numbers in a fuzzy set. This method is chosen as the most appropriate method due to its general, easy use and consistency in results Pattnaik (2012). This method is an approach for ranking a fuzzy number set with a way that combines minimizing set and maximizing set approaches. The membership functions of maximizing set $M$ and minimizing set $G$ for a trapezoidal fuzzy number $A_{i}=\left(c_{i}, a_{i}\right.$, $\left.\mathrm{b}_{\mathrm{i}}, \mathrm{d}_{\mathrm{i}}\right)$ are:

$$
\begin{gathered}
\mu_{M}(x)=\left\{\begin{array}{cc}
{\left[\frac{x-x_{\min }}{x_{\max }-x_{\min }}\right]^{k},} & x_{\min } \leq x \leq x_{\max } \\
0, & \text { otherwise }
\end{array}\right. \\
\mu_{G}(x)=\left\{\begin{array}{cc}
{\left[\frac{x-x_{\max }}{x_{\min }-x_{\max }}\right]^{k},} & x_{\min } \leq x \leq x_{\max } \\
0, & \text { otherwise }
\end{array}\right.
\end{gathered}
$$

$\mathrm{X}_{\max }=\sup \mathrm{S}, \mathrm{x}_{\min }=\inf \mathrm{S}$,

$$
S=\bigcup_{i=1}^{n} S_{i}, S_{i}=\operatorname{des} A_{i} S_{i}=\operatorname{des} A_{i}
$$

The linear case is given by $\mathrm{k}=1$ (risk neutral), while $\mathrm{k}$ $>1$ represents risk-prone (convex) membership functions, and $0<\mathrm{k}<1$ represents risk-averse (concave) membership functions. In here, the value of $\mathrm{k}$ is assigned to be 1 . When $\mathrm{k}$
$=1$ the ranking value of $A_{i}$ is calculated using the following expression:

$$
\begin{aligned}
& U_{T}(i)=\frac{1}{2} \times\left[\frac{\left(d_{i}-x_{\min }\right)}{\left(\left(x_{\max }-x_{\min }\right)-\left(b_{i}-d_{i}\right)\right)}+\frac{1-\left(x_{\max }-c_{i}\right)}{\left(\left(x_{\max }-x_{\min }\right)-\left(a_{i}-c_{i}\right)\right)}\right], \\
& \mathrm{i}=1,2, \ldots . \mathrm{n}
\end{aligned}
$$

\section{NUMERICAL EXAMPLE}

Suppose that in a manufacturing company, five experts (DM) are identified to evaluate 20 manpower alternatives $\left(\mathrm{T}_{\mathrm{i}}, \mathrm{i}=1,2 \ldots 20\right)$ in four performance criteria. These are delivery, quality, flexibility and service.

The decision makers utilize a linguistic set of weights that are stated in step I, to identify the importance of each criterion. The weights assigned to the seven criteria by the five decision makers are given Table-1.

I assume that the decision makers use the linguistic variable set given in step II, to assess the suitability of the manpower alternative under each of the subjective criteria. The linguistic ratings are presented (illustrated) in Tables 23 .

Table1. The Importance Weights of the Decision Criteria

\begin{tabular}{|c|c|c|c|c|c|}
\hline $\begin{array}{c}\text { Decision } \\
\text { Criteria }\end{array}$ & $\mathrm{DM}_{1}$ & $\mathrm{DM}_{2}$ & $\mathrm{DM}_{3}$ & $\mathrm{DM}_{4}$ & $\mathrm{DM}_{5}$ \\
\hline Delivery & $\mathrm{VH}$ & $\mathrm{VH}$ & $\mathrm{VH}$ & $\mathrm{H}$ & $\mathrm{H}$ \\
\hline Quality & $\mathrm{VH}$ & $\mathrm{H}$ & $\mathrm{M}$ & $\mathrm{H}$ & $\mathrm{M}$ \\
\hline Flexibility & $\mathrm{H}$ & $\mathrm{VH}$ & $\mathrm{H}$ & $\mathrm{VH}$ & $\mathrm{VH}$ \\
\hline Service & $\mathrm{H}$ & $\mathrm{H}$ & $\mathrm{M}$ & $\mathrm{L}$ & $\mathrm{VL}$ \\
\hline
\end{tabular}

The aggregate weights for each criterion are calculated by grouping the linguistic assessments of the five decision makers. The aggregate weights calculated by employing equation in step IV are given below:

$\mathrm{W}_{1}=(0.68,0.92,0.92,1) \quad \mathrm{W}_{2}=(0.48,0.72,0.72,0.88)$

$\mathrm{W}_{3}=(0.68,0.92,0.92,1) \quad \mathrm{W}_{4}=(0.26,0.46,0.46,0.66)$

The fuzzy performance values for all manpower alternatives in each criterion are computed by using equation in Step V. The results are shown in Tables 4-5.

Fuzzy suitability index values for the manpower alternatives are obtained by averaging the products of weights and linguistic ratings over all the criteria via a weighted mean operator. The results are illustrated in Table 6.

The equation in step VII is used to determine the ranking values of the manpower alternatives. The ranking of the manpowers are given in Table 6 . From the table, $\mathrm{T}_{4}$ appears to be the best manpower alternative as a result of the decision procedure, and thus is the first one to be considered for purchasing selections. 
Table 2.The Decision Makers' Evaluation of the Manpowers for Quality Performance

\begin{tabular}{|c|c|c|c|c|c|c|c|c|c|c|}
\hline \multirow[t]{2}{*}{ Manpower } & \multicolumn{5}{|c|}{ Delivery } & \multicolumn{5}{|c|}{ Quality } \\
\hline & $D_{1}$ & $D_{2}$ & $D_{3}$ & $D_{4}$ & $D_{5}$ & $\mathrm{D}_{1}$ & $\mathrm{D}_{2}$ & $D_{3}$ & $D_{4}$ & $D_{5}$ \\
\hline $\mathrm{T}_{1}$ & $M \& G$ & $M$ & G & G & $M$ & VP\&P & $M \& G$ & G\&VG & $M$ & $M$ \\
\hline $\mathrm{T}_{2}$ & VP & VG & G & VG & $M$ & $P$ & $G$ & $G$ & G\&VG & M \\
\hline$T_{3}$ & M\&G & $M \& G$ & P\&M & $G$ & $P$ & VG & VG & $P$ & G\&VG & $P$ \\
\hline $\mathrm{T}_{4}$ & VG & $\mathrm{P}$ & G\&VG & $G$ & $M \& G$ & VG & VG & $\mathrm{P}$ & VG & $M \& G$ \\
\hline$T_{5}$ & $M$ & $\mathrm{VP}$ & P\&M & $P$ & VP\&P & P\&M & $G$ & $\mathrm{P}$ & G\&VG & VP\&P \\
\hline $\mathrm{T}_{6}$ & P\&M & VG & $G$ & $M$ & G\&VG & $M$ & VG & $\mathrm{P}$ & VP & G\&VG \\
\hline $\mathrm{T}_{7}$ & VP\&P & P\&M & VG & $\mathrm{P}$ & $M \& G$ & VG & $M \& G$ & $M$ & VP\&P & $M \& G$ \\
\hline $\mathrm{T}_{8}$ & $G$ & VP\&P & VP & $P$ & $P \& M$ & $\mathrm{VP}$ & $M \& G$ & $G$ & $M$ & $P \& M$ \\
\hline$T_{9}$ & P\&M & $G$ & $M$ & $\mathrm{M} \& \mathrm{H}$ & $\mathrm{VP}$ & P\&M & $G$ & $M \& G$ & $\mathrm{P}$ & $\mathrm{VP}$ \\
\hline$T_{10}$ & VP\&P & $G$ & $\mathrm{VP}$ & $P \& M$ & $M$ & P\&M & $\mathrm{VP}$ & VP & $\mathrm{P}$ & $M$ \\
\hline$T_{11}$ & $G$ & $M$ & VP\&P & $\mathrm{VP}$ & $M \& G$ & $\mathrm{VP}$ & $M \& G$ & VP\&P & VG & $M \& G$ \\
\hline$T_{12}$ & $G$ & $M \& G$ & $\mathrm{VP}$ & $M$ & M\&G & G\&VG & $M \& V G$ & $M$ & G\&VG & $M \& G$ \\
\hline$T_{13}$ & VP & P\&M & G\&VG & P\&M & $M$ & $P \& M$ & $M$ & $M \& G$ & G\&VG & $M$ \\
\hline $\mathrm{T}_{14}$ & VG & G\&VG & G\&VG & $P \& M$ & M\&G & $P \& M$ & $P \& M$ & VG & $\mathrm{P} \& \mathrm{M}$ & $M \& G$ \\
\hline$T_{15}$ & $P$ & $\mathrm{P}$ & VG & $M$ & G\&VG & $P$ & G\&VG & VG & $G$ & $G$ \\
\hline$T_{16}$ & P\&M & $\mathrm{P}$ & $M$ & $G$ & G\&VG & $M \& G$ & $G$ & $G$ & $M$ & $\mathrm{VP}$ \\
\hline$T_{17}$ & $G$ & VP\&P & VG & G\&VG & $P \& M$ & $\mathrm{VP}$ & $G$ & VG & $M$ & VP\&P \\
\hline$T_{18}$ & VG & $\mathrm{VP}$ & G\&VG & M\&G & VP\&M & M\&G & $P \& M$ & $G$ & $\mathrm{P}$ & VP \\
\hline$T_{19}$ & $M$ & $M$ & $P \& M$ & VP\&P & $M$ & VG & G\&VG & G & $M \& G$ & G\&VG \\
\hline $\mathrm{T}_{20}$ & $M \& G$ & G & VP\&P & VG & G & $M$ & $P \& M$ & $P$ & VP\&P & G\&VG \\
\hline
\end{tabular}

Table 3. The Decision Makers' Evaluation of the Manpowers for Flexibility and Service Performance

\begin{tabular}{|c|c|c|c|c|c|c|c|c|c|c|}
\hline \multirow[t]{2}{*}{ Manpower } & \multicolumn{5}{|c|}{ Flexibility } & \multicolumn{5}{|c|}{ Service } \\
\hline & $D_{1}$ & $D_{2}$ & $D_{3}$ & $D_{4}$ & $D_{5}$ & $D_{1}$ & $\mathrm{D}_{2}$ & $D_{3}$ & $\mathrm{D}_{4}$ & $D_{5}$ \\
\hline $\mathrm{T}_{1}$ & VG & $M$ & $M \& G$ & G\&VG & G & $M$ & $P$ & VG & VP & VP \\
\hline $\mathrm{T}_{2}$ & $P$ & M & $M$ & VP & VG & M & $P \& M$ & VP & $G \& V G$ & $G$ \\
\hline$T_{3}$ & VP\&P & P\&M & VG & $M$ & G\&VG & $P$ & $G$ & $P$ & VG & VG \\
\hline $\mathrm{T}_{4}$ & G\&VG & G\&VG & $M \& G$ & $G$ & P\&M & $M \& G$ & $\mathrm{P}$ & $P \& M$ & $\mathrm{P}$ & VG \\
\hline$T_{5}$ & $\mathrm{P}$ & $M \& G$ & VG & VG & $M \& G$ & VP\&P & $P$ & $P \& M$ & $M$ & $P \& M$ \\
\hline $\mathrm{T}_{6}$ & VP\&P & VP & $M$ & VP & VP & $P \& M$ & $\mathrm{P}$ & G\&VG & G & VG \\
\hline $\mathrm{T}_{7}$ & $\mathrm{VP}$ & $\mathrm{VP}$ & $\mathrm{VP}$ & P\&M & VP & $G$ & $G \& V G$ & $P \& M$ & $G$ & $M \& G$ \\
\hline $\mathrm{T}_{8}$ & VG & $\mathrm{VP}$ & $M \& G$ & $G$ & G\&VG & $G$ & VP \& P & $M \& G$ & VG & $G$ \\
\hline$T_{9}$ & G\&VG & VG & G\&VG & $M$ & VP\&P & $M \& G$ & VP \& P & $M$ & $\mathrm{P}$ & $G$ \\
\hline$T_{10}$ & V\&VG & $G$ & $G$ & VG & $\mathrm{P}$ & VG & $G \& V G$ & VG & $M \& G$ & $P \& M$ \\
\hline$T_{11}$ & $\mathrm{VP}$ & $M \& G$ & $\mathrm{VP}$ & $M \& G$ & $M$ & P\&M & $G$ & $P \& M$ & $G$ & VP \& P \\
\hline$T_{12}$ & $\mathrm{VP}$ & VP\&P & $M$ & VPP & $M$ & VG & $P \& M$ & $P \& M$ & VP & $M \& G$ \\
\hline$T_{13}$ & $G$ & $P$ & VP\&P & $M \& G$ & P\&M & VG & $P \& M$ & VP \& $P$ & $G$ & $P$ \\
\hline$T_{14}$ & VP\&P & $\mathrm{P}$ & $M \& G$ & $G$ & $M \& G$ & $G$ & VG & $M \& G$ & M & M \\
\hline$T_{15}$ & $M \& G$ & VP\&P & $M \& G$ & VPP & GG & VP & $P$ & $G$ & $M$ & $M$ \\
\hline$T_{16}$ & $G$ & VG & $P$ & $\mathrm{VP}$ & VGVG & $\mathrm{P}$ & $\mathrm{VP}$ & $M$ & VP & VG \\
\hline$T_{17}$ & $M \& G$ & P\&M & $M$ & VG & G\&VG & P\&M & $G \& V G$ & $M$ & $G$ & VP \\
\hline$T_{18}$ & VG & G\&VG & VG & $M \& G$ & G & G & VG & $P$ & VG & $P$ \\
\hline$T_{19}$ & $M$ & $\mathrm{VP}$ & $G$ & P\&M & P\&M & $P$ & $P$ & $M \& G$ & VG & $P \& M$ \\
\hline $\mathrm{T}_{20}$ & $M$ & $P$ & P\&M & $G$ & VG & $P$ & $M$ & VP \& P & $P \& M$ & $P \& M$ \\
\hline
\end{tabular}


Pattnaik : Skilled Manpower Selection for Micro, Small and Medium Enterprises: A Fuzzy Decision Making Approach

Table 4. The Average Linguistic Ratings of Manpower Alternatives for Delivery and Quality Criteria

\begin{tabular}{|c|c|c|c|c|c|c|c|c|}
\hline \multirow{2}{*}{$\begin{array}{c}\begin{array}{c}\text { Man } \\
\text { power }\end{array} \\
T_{1}\end{array}$} & \multicolumn{4}{|c|}{ Delivery } & \multicolumn{4}{|c|}{ Quality } \\
\hline & 0.42 & 0.62 & 0.68 & 0.88 & 0.30 & 0.46 & 0.60 & 0.76 \\
\hline $\mathrm{T}_{2}$ & 0.50 & 0.66 & 0.66 & 0.78 & 0.42 & 0.62 & 0.66 & 0.82 \\
\hline$T_{3}$ & 024 & 0.44 & 0.62 & 0.82 & 0.44 & 0.64 & 0.68 & 0.76 \\
\hline$T_{4}$ & 0.46 & 0.66 & 0.76 & 0.88 & 0.54 & 0.74 & 0.80 & 0.88 \\
\hline $\mathrm{T}_{5}$ & 0.06 & 0.18 & 0.28 & 0.48 & 0.24 & 0.40 & 0.54 & 0.70 \\
\hline $\mathrm{T}_{6}$ & 0.46 & 0.66 & 0.76 & 0.88 & 0.34 & 0.50 & 0.54 & 0.66 \\
\hline $\mathrm{T}_{7}$ & 0.22 & 0.38 & 0.54 & 0.70 & 0.34 & 0.50 & 0.66 & 0.82 \\
\hline $\mathrm{T}_{8}$ & 0.12 & 0.24 & 0.34 & 0.54 & 0.24 & 0.40 & 0.52 & 0.72 \\
\hline$T_{9}$ & 0.24 & 0.40 & 0.52 & 0.72 & 0.18 & 0.34 & 0.46 & 0.66 \\
\hline$T_{10}$ & 0.18 & 0.30 & 0.40 & 0.60 & 0.06 & 0.18 & 0.24 & 0.44 \\
\hline$T_{11}$ & 0.24 & 0.36 & 0.46 & 0.66 & 0.28 & 0.40 & 0.56 & 0.72 \\
\hline $\mathrm{T}_{12}$ & 0.30 & 0.46 & 0.58 & 0.78 & 0.48 & 0.68 & 0.86 & 0.94 \\
\hline$T_{13}$ & 0.18 & 0.34 & 0.50 & 0.66 & 0.30 & 0.50 & 0.66 & 0.82 \\
\hline $\mathrm{T}_{14}$ & 0.46 & 0.66 & 0.86 & 0.94 & 0.22 & 0.42 & 0.66 & 0.82 \\
\hline$T_{15}$ & 0.34 & 0.54 & 0.58 & 0.70 & 0.52 & 0.72 & 0.76 & 0.88 \\
\hline$T_{16}$ & 0.30 & 0.50 & 0.60 & 0.76 & 0.36 & 0.52 & 0.58 & 0.78 \\
\hline $\mathrm{T}_{17}$ & 0.40 & 0.56 & 0.70 & 0.82 & 0.34 & 0.46 & 0.50 & 0.66 \\
\hline $\mathrm{T}_{18}$ & 0.34 & 0.46 & 0.60 & 0.72 & 0.18 & 0.34 & 0.46 & 0.66 \\
\hline $\mathrm{T}_{19}$ & 0.18 & 0.34 & 0.44 & 0.64 & 0.58 & 0.78 & 0.92 & 1.00 \\
\hline $\mathrm{T}_{20}$ & 0.46 & 0.62 & 0.72 & 0.88 & 0.18 & 0.34 & 0.48 & 0.64 \\
\hline
\end{tabular}

Table 5. The Average Linguistic Ratings of Manpower Alternatives for Flexibility and Service Criteria

\begin{tabular}{|c|l|l|l|l|l|l|l|l|}
\hline Manpower & \multicolumn{9}{|c|}{ Flexibility } & \multicolumn{4}{c|}{ Service } \\
\hline $\mathrm{T}_{1}$ & 0.52 & 0.72 & 0.82 & 0.94 & 0.22 & 0.34 & 0.34 & 0.50 \\
\hline $\mathrm{T}_{2}$ & 0.28 & 0.44 & 0.44 & 0.60 & 0.30 & 0.46 & 0.56 & 0.72 \\
\hline $\mathrm{T}_{3}$ & 0.34 & 0.50 & 0.64 & 0.76 & 0.44 & 0.64 & 0.64 & 0.76 \\
\hline $\mathrm{T}_{4}$ & 0.42 & 0.62 & 0.82 & 0.94 & 0.22 & 0.42 & 0.54 & 0.70 \\
\hline $\mathrm{T}_{5}$ & 0.44 & 0.64 & 0.76 & 0.88 & 0.06 & 0.22 & 0.38 & 0.58 \\
\hline $\mathrm{T}_{6}$ & 0.06 & 0.10 & 0.14 & 0.34 & 0.40 & 0.60 & 0.70 & 0.82 \\
\hline $\mathrm{T}_{7}$ & 0.00 & 0.04 & 0.10 & 0.30 & 0.42 & 0.62 & 0.78 & 0.94 \\
\hline $\mathrm{T}_{8}$ & 0.46 & 0.62 & 0.72 & 0.84 & 0.46 & 0.62 & 0.72 & 0.88 \\
\hline $\mathrm{T}_{9}$ & 0.46 & 0.62 & 0.74 & 0.82 & 0.24 & 0.40 & 0.50 & 0.70 \\
\hline $\mathrm{T}_{10}$ & 0.52 & 0.72 & 0.76 & 0.88 & 0.50 & 0.70 & 0.86 & 0.94 \\
\hline $\mathrm{T}_{11}$ & 0.18 & 0.30 & 0.42 & 0.62 & 0.24 & 0.40 & 0.56 & 0.76 \\
\hline $\mathrm{T}_{12}$ & 0.12 & 0.20 & 0.28 & 0.48 & 0.22 & 0.38 & 0.56 & 0.72 \\
\hline $\mathrm{T}_{13}$ & 0.18 & 0.34 & 0.50 & 0.70 & 0.28 & 0.44 & 0.54 & 0.70 \\
\hline $\mathrm{T}_{14}$ & 0.24 & 0.40 & 0.56 & 0.76 & 0.46 & 0.66 & 0.72 & 0.88 \\
\hline $\mathrm{T}_{15}$ & 0.24 & 0.36 & 0.56 & 0.76 & 0.24 & 0.40 & 0.40 & 0.60 \\
\hline $\mathrm{T}_{16}$ & 0.44 & 0.60 & 0.60 & 0.72 & 0.22 & 0.34 & 0.34 & 0.50 \\
\hline $\mathrm{T}_{17}$ & 0.40 & 0.60 & 0.76 & 0.88 & 0.30 & 0.46 & 0.58 & 0.72 \\
\hline $\mathrm{T}_{18}$ & 0.62 & 0.82 & 0.92 & 1.00 & 0.44 & 0.64 & 0.64 & 0.76 \\
\hline $\mathrm{T}_{19}$ & 0.18 & 0.34 & 0.46 & 0.66 & 0.22 & 0.42 & 0.54 & 0.70 \\
\hline $\mathrm{T}_{20}$ & 0.34 & 0.54 & 0.60 & 0.76 & 0.06 & 0.22 & 0.38 & 0.58 \\
\hline
\end{tabular}


Table 6. Fuzzy Suitability Index Values for the Manpower Alternatives and Ranking of the Manpower Alternatives

\begin{tabular}{|c|c|c|c|c|c|c|c|}
\hline \multirow{2}{*}{$\begin{array}{c}\text { Man } \\
\text { power }\end{array}$} & \multicolumn{4}{|c|}{ Fuzzy Preference Index } & \multicolumn{3}{|c|}{ Ranking of the Manpower Alternatives } \\
\hline & C & A & B & $d$ & Ranking & Manpower (Ti) & Ranking Value \\
\hline $\mathrm{T}_{1}$ & 0.2101 & 0.4301 & 0.4921 & 0.7047 & 1 & $\mathrm{~T}_{4}$ & 0.6191 \\
\hline $\mathrm{T}_{2}$ & 0.2005 & 0.4175 & 0.4362 & 0.6442 & 2 & $\mathrm{~T}_{18}$ & 0.6057 \\
\hline $\mathrm{T}_{3}$ & 0.1800 & 0.4050 & 0.4858 & 0.6876 & 3 & $\mathrm{~T}_{14}$ & 0.6001 \\
\hline $\mathrm{T}_{4}$ & 0.2287 & 0.4529 & 0.5695 & 0.7641 & 4 & $\mathrm{~T}_{1}$ & 0.5977 \\
\hline$T_{5}$ & 0.1177 & 0.2859 & 0.4261 & 0.5897 & 5 & $\mathrm{~T}_{17}$ & 0.5911 \\
\hline $\mathrm{T}_{6}$ & 0.1552 & 0.3338 & 0.3847 & 0.5855 & 6 & $T_{3}$ & 0.5736 \\
\hline $\mathrm{T}_{7}$ & 0.1055 & 0.2349 & 0.3557 & 0.5855 & 7 & $T_{2}$ & 0.5617 \\
\hline $\mathrm{T}_{8}$ & 0.1573 & 0.3227 & 0.4202 & 0.6483 & 8 & $\mathrm{~T}_{16}$ & 0.5590 \\
\hline $\mathrm{T}_{9}$ & 0.1562 & 0.3234 & 0.4301 & 0.6457 & 9 & $\mathrm{~T}_{15}$ & 0.5554 \\
\hline $\mathrm{T}_{10}$ & 0.1587 & 0.3245 & 0.4089 & 0.6219 & 10 & $\mathrm{~T}_{9}$ & 0.5464 \\
\hline $\mathrm{T}_{11}$ & 0.1206 & 0.2514 & 0.3676 & 0.6038 & 11 & $T_{8}$ & 0.5447 \\
\hline $\mathrm{T}_{12}$ & 0.1433 & 0.3179 & 0.4170 & 0.6406 & 12 & $\mathrm{~T}_{20}$ & 0.5441 \\
\hline $\mathrm{T}_{13}$ & 0.1154 & 0.2970 & 0.4109 & 0.6359 & 13 & $\mathrm{~T}_{10}$ & 0.5356 \\
\hline $\mathrm{T}_{14}$ & 0.1753 & 0.3953 & 0.5282 & 0.7506 & 14 & $\mathrm{~T}_{12}$ & 0.5309 \\
\hline$T_{15}$ & 0.1766 & 0.3826 & 0.4450 & 0.6576 & 15 & $\mathrm{~T}_{19}$ & 0.5308 \\
\hline $\mathrm{T}_{16}$ & 0.1833 & 0.3351 & 0.4195 & 0.6241 & 16 & $T_{6}$ & 0.5128 \\
\hline$T_{17}$ & 0.1963 & 0.4025 & 0.4925 & 0.6890 & 17 & $T_{13}$ & 0.5092 \\
\hline $\mathrm{T}_{18}$ & 0.2134 & 0.4292 & 0.5060 & 0.7006 & 18 & $T_{5}$ & 0.5083 \\
\hline $\mathrm{T}_{19}$ & 0.1451 & 0.3451 & 0.4209 & 0.6605 & 19 & $\mathrm{~T}_{11}$ & 0.5042 \\
\hline $\mathrm{T}_{20}$ & 0.1615 & 0.3533 & 0.4337 & 0.6465 & 20 & $\mathrm{~T}_{7}$ & 0.4868 \\
\hline
\end{tabular}

\section{CONCLUSION}

There have been many methods proposed for the modeling of the manpower selection process. However they cannot meet the real choice process with performance evaluation because most of the existing methods are mathematical models. But this is a real critical subject for a decision maker that can result in choosing manpower with an insufficient performance.

The method that this paper presents here is an easy and realistic approach for manpower selection. The most important part of the FMSA is that it gives a concrete result by recording the purchasing experts' previous experience and processes these with fuzzy logic arithmetic. Briefly, results in this paper not only provide a valuable reference for decision makers in selecting a right vendor for a right product but also provide a useful algorithm for many organizations that use the decision rule to improve their total operation cost in the real world. In this regard, the proposed algorithm presented in this paper may be more realistic for some real world problems. Ranking of manpower alternatives with an example problem generated results which are consistent with the expectations. So it indicates some flexibility to cover many decisions in fuzzy scenarios. The proposed algorithm can be extended in several ways. As a further study, it is possible to develop this method by using numerical performance criteria via DFA in order to use objective and subjective evaluations together.

\section{REFERENCES}

Albino, V., and Garavelli, A.C. (1998). A neural network application to subcontractor rating in construction firms. International Journal of Project Management, 16(1), pp. 9-14.

Baldwin, J.F., and Guild, N.C.F. (1979). Comparison of fuzzy sets on the same decision space, Fuzzy Sets \& Systems, 2, pp. 213-231.

Barbarosoglu, G., and Yazgac, T. (1997). An application of the analytic hierarchy process to the supplier selection problem. Production \&Inventory Management Journal, 1st quarter, pp. 14-21.

Burt, D.N. (1989), Managing product quality through strategic purchasing. Sloan Management Review, 30(1), pp. 39-47.

Campos, I.M., and Munoz, A. (1989). A subjective approach for ranking fuzzy subsets. Fuzzy Sets \& Systems, 29, pp. 145-153.

Chang, P.T., and Lee, E.S. (1994). Ranking of fuzzy sets based on the concept of existence. Computer\& Mathematics with Applications, 27(9), pp. 121.

Chaudhry, S.S., Forst, F.G., and Zydiak, J.L. (1993). Vendor selection with price breaks. European Journal of Operational Research, 70, pp. 52-66.

Chen, S.H. (1958). Ranking Fuzzy numbers with maximising set and minimising set. Fuzzy Sets \& Systems, 17, pp. 113-129. 
De Boer, L. (1998). Operations research in support of purchasing. Design of a toolbox for supplier selection. Ph.D. Thesis, University of Twente, Enschede, The Netherlands.

De Boer, L. (2001). A review of methods supporting supplier selection. European Journal of Purchasing \&Supply Management, 7 , pp. 75-89.

Dubois, D., and Prade, H. (1983). Ranking fuzzy numbers in the setting of possibility theory. Information Science, 30, pp. 183-224.

Ellram, L.M., and Carr, A.S. (1994). Strategic purchasing: A history and review of the literature. International Journal of Purchasing \&Materials Management, 30(2), pp. 1018.

Fortemps, P., and Roubens, M. (1996). Ranking and defuzzification methods based on area compensation. Fuzzy Sets \& Systems, 82, pp. 319-330.

Giuliana, P., and Francesco, P. (2012). Young people, the disabled, and immigrant workers: An introduction and some policy recommendations. International Journal of Manpower, 33(1), pp. 4-8.

Hien, N., Laporte, G., and Roy, J. (2009). Business environment factors, incoterms selection and export performance. Operations and Supply Chain Management, 2(2), pp. 125-135.

Holt, G.D. (1998). Which contractor selection methodology? International Journal of Project Management, 16(3), pp. 153-164.

Khanle, P., and Vaingankar, A. (2006). Estimating availability of middle level skilled manpower. The Turkish Online Journal Educational Technology, 5(2), pp. 24-27.

Khoo, L.P., Tor, S.B., and Lee, S.S.G. (1998). The potential of intelligent software agents in the World Wide Web in the automated part procurement. International Journal of Purchasing \&Materials Management, 34(1), pp. 4652.

Kim, K., and Park, K.S. (1990). Ranking fuzzy numbers with index of optimism. Fuzzy Sets and Systems, 35, pp. 143150.

Li, C.C., Fun, Y.P., and Hung, J.S. (1997). A new measure for supplier performance evaluation. IIE Transactions, 29, pp. 753-758.

Liang, G.S., and Wang, M.J.J. (1991). A Fuzzy multi-criteria decision-making method for facility site selection, International Journal of Production Research, 50, pp. 247- 255.

Lin, S.S., and Juang, Y.S. (2008). Selecting green suppliers with analytic hierarchy process for biotechnology industry. Operations and Supply Chain Management1(2), pp. 115-129.

Min, H. (1994). International supplier selection: a multiattribute utility approach. International Journal of Physical Distribution of Logistics Management, 24(5), pp. 24-33.

Monczka, R.M., Trecka, R.J., and Handfield, R.B. (1998). Purchasing and Supply Chain Management. (SouthWestern: Cincinnati, OH).

Narasimhan, R. (1983). An analytic approach to supplier selection. Journal of Purchasing and Materials Management, 1, pp. 27-32.
Núria, Q., and Silvio, R. (2012). Occupational selection in multilingual labor markets: the case of Catalonia, International Journal of Manpower, 33 (8), pp. 918-937.

Nydick, R.L., and Hill, R.P. (1992). Using the Analytic Hierarchy Process to structure the supplier selection procedure. International Journal of Purchasing and Materials Management, 28(2), pp. 31-36.

Pan, A.C. (1989). Allocation of order quantities among suppliers. Journal of Purchasing Materials Management, 25(2), pp. 36-39.

Pattnaik, M. (2012). A Note on Non Linear ProfitMaximization Entropic Order Quantity (EnOQ) Model for Deteriorating Items with Stock Dependent Demand Rate. Operations and Supply Chain Management 5(2), 97-102.

Pattnaik, M. (2012). Models of Inventory Control, Lambart Academic Publishing, Germany.

Peneva, V., and Popchev, I. (1998). Comparison of clusters from fuzzy numbers. Fuzzy Sets \& Systems, 97, pp. 7581.

Petroni, A., and Braglia, M. (2000). Vendor selection using principal component analysis. Journal of Supply Chain Management, 36(2), pp. 63-69.

Raj, P.A., and Kumar, D.N. (1999). Ranking alternatives with fuzzy weights using maximizing set and minimizing set. Fuzzy Sets and Systems, 105, pp. 365375.

Ronen, B., and Trietsch, D. (1988). A decision support system for purchasing management of large projects. Operations Research, 36(6), pp. 882-890.

Rosenthal, E.C., Zydiak, J.L., and Chaudhry, S.S. (1995). Vendor selection with bundling. Decision Science, 26(1), pp. 35-48.

Sadrian, A.A., and Yoon, Y.S. (1994). A procurement decision support system in business volume discount environments. Operation Research, 42(1), pp. 14-23.

Sarkis, J., and Talluri, S. (2000). A model for strategic supplier selection, in Proceedings of the 9th International IPSERA Conference, edited by $\mathrm{M}$. Leenders, Richard Ivey Business School, London, Ontario, pp. 652-661.

Smytka, D.L., and Clemens, M.W. (1993). Total cost supplier selection model: a case study. International Journal of Purchasing Material Management, 29(1), pp. 42-49.

Soukup, W.R. (1987). Supplier selection strategies. Journal of Purchasing and Materials Management, 23(3), pp. 7 12.

Timmerman, E. (1986). An approach to vendor performance evaluation. Journal of Purchasing \&Supply Management, 1, pp. 27-32.

Vicente, R.P., Inmaculada, B.M., and Mercedes, S.C. (2012). Commitment to employees, labor intensity, and labor productivity in small firms: A non-linear approach International Journal of Manpower, 33 (8), pp.938-954.

Vokurka, R.J., Choobineh, J., and Vadi, L. (1996). A prototype expert system for the evaluation and selection of potential suppliers. International Journal of Operations \&Production Management, 16(12), pp. 106127.

Von Altrock, C. (1997). Fuzzy Logic and Neuro Fuzzy Applications on Business and Finance. Prentice - Hall: Englewood Cliffs, New Zealand. 
Weber, C.A. (1991). A Decision Support System Using Multi Criteria Techniques for vendor Selection. (University Microfilms International: Ann Arbor, MI).

Weber, C.A., and Desai, A. (1996). Determination of paths to vendor market efficiency using parallel coordinates representation: A negotiation tool for buyers. European Journal of Operational Research, 90, pp. 142-155.

Weber, C.A., Current, J.R., and Desai, A. (2000). An optimization approach to determining the number of vendors to employ. Supply Chain Management: An International Journal, 5(2), pp. 90-98.
Williams, R.F. (1984). Purchasing Criteria for the Inherently Complex New Product. (University Microfilms International: Ann Arbor, $M I)$.

Zadeh, L.A. (1965). Fuzzy sets. Information Control, 8, pp. 338-353.

Zenz, G. (1981). Purchasing and the Management of Materials, Wiley, New York.

Zimmerman, H.J., and Zysno, P. (1983). Decisions and evaluations by hierarchical aggregation of information. Fuzzy Sets \& Systems, 10, pp. 243-266.

Dr. Monalisha Pattnaik is lecturer of Department of Business Administration at Utkal University, Odisha, India. She received her $\mathrm{Ph}$. D. in Operations Research (Statistics) from Utkal University. Her research interests cover areas in Operations Research, Production Planning, Inventory Control, Project Management, Operations Management, General Management, Fuzzy Sets, Applied Statistics, Applied Mathematics, Decision Sciences and Optimization. Dr. Monalisha is an editor of some international journals e.g. Journal of Business Management and Economics, General Mathematics Notes, The Journal of Mathematics and Computer Science and Thailand Statistician. She has published several articles in numerous international journals e.g. Applied Mathematical Sciences, Pakistan Journal of Statistics and Operations Research, International Mathematical Forum, The Open Operational Research Journal, International Journal of Scientific and Statistical Computing, International Journal of Management Science and Engineering Management, International Journal of Contemporary Mathematical Sciences, Thailand Statistician, The Journal of Mathematics and Computer Science. 